\title{
Cloning and Expression of a Fibrinolytic Enzyme Gene, aprECJ1, from Bacillus velezensis $\mathrm{CJ} 1$ Isolated from Myeolchi Jeotgal
}

\author{
Ji Yeon Yoo ${ }^{1}$, Zhuang Yao ${ }^{1}$, Se Jin Lee ${ }^{1}$, Hye Sung Jeon ${ }^{1}$, and Jeong Hwan Kim ${ }^{1,2 *}$ \\ ${ }^{1}$ Division of Applied Life Science (BK21 Four), Graduate School, ${ }^{2}$ Institute of Agriculture and Life Science, Gyeongsang National University, \\ Jinju 52828, Republic of Korea
}

Received: April 21, 2021 / Revised: May 7, 2021 / Accepted: May 14, 2021

\begin{abstract}
Bacillus velezensis CJ1, showing significant fibrinolytic activity, was isolated from Myeolchi Jeotgal, a popular Korean fermented seafood. When B. velezensis CJ1 was grown on four different culture media, the culture on the Luria-Bertani (LB) broth showed the highest fibrinolytic activity (102.94 $\mathrm{mU} / \mathrm{\mu l})$ at $48 \mathrm{~h}$. LB was also the best medium for growth. SDS-PAGE of culture supernatant showed four major bands, 38, 35, 27, and $22 \mathrm{kDa}$ in size. Fibrin zymography showed four active bands, 50, 47, 40, and $30 \mathrm{kDa}$ in size. A gene homologous to aprE of the Bacillus species was cloned by PCR. DNA sequencing showed that aprECJ1 can encode a protease consisting of 382 amino acids. The translated amino acid sequence of AprECJ1 showed high identity values with those of $B$. velezensis strains and other Bacillus species. The aprECJ1 gene was introduced into B. subtilis WB600 using an $E$. coli-Bacillus shuttle vector, pHY300PLK, and overexpressed. A $27 \mathrm{kDa}$ band corresponding to the mature form of AprECJ1 was produced and confirmed by SDS-PAGE and fibrin zymography. B. subtilis WB600 [pHYaprECJ1] showed 1.8-fold higher fibrinolytic activity than $B$. velezensis $\mathrm{CJ} 1$ at $48 \mathrm{~h}$.
\end{abstract}

Keywords: Fibrinolytic enzyme, Bacillus velezensis, Myeolchi Jeotgal, gene expression

\section{Introduction}

Many Bacillus species secrete several proteases into culture medium, and some enzymes possess strong fibrinolytic activities [1]. Recently, these bacilli fibrinolytic enzymes gain interests due to their potential as an alternative to drugs such as t-PA (tissue plasminogen activator), streptokinase or urokinease used for treating thrombosis, one of the top leading causes of human death worldwide [2]. These drugs have some shortcomings, i.e. expensive, short half-lives inside body, and may cause internal bleeding. Scientists have been trying to isolate more safe and effective fibrinolytic enzymes from

*Corresponding author

Tel.: +82-55-772-1904, Fax: +82-55-772-1909

E-mail: jeonghkm@gnu.ac.kr plants, animals and microorganisms [3]. Among them, fibrinolytic enzymes from bacilli seem to have the most desirable properties. Bacillus species have been used for various fermented foods for a long time, and the organisms and their enzymes are considered generally recognized as safe (GRAS) class. In addition, bacilli can be cultivated easily in large-scale and economically [4]. Nattokinase produced by some $B$. subtilis strains is the most well-known fibrinolytic enzyme and currently sold as a nutritional supplement [5]. Some clinic studies showed the effectiveness of Nattokinase for treating thrombosis in vivo [6].

Isolation of novel Bacillus species with strong fibrinolytic activities is essential for extending applications of bacilli fibrinolytic enzymes. Among the diverse natural environments, traditional Asian fermented foods are the best sources for bacilli [7]. Fibrinolytic Bacillus strains 
including $B$. subtilis, B. amyloliquefaciens and $B$. licheniformis have been isolated from Cheonggukjang and Doenjang from Korea [8, 9], Natto from Japan [10], and Douchi from China [11].

$B$. velezensis is closely related to $B$. subtilis and $B$. amyloliquefaciens, and synonymous to various strains of B. amyloliquefaciens ssp. plantarum and B. methylotrophicus strains [12].

B. velezensis is an important member of PGPR (plant growth promoting rhizobacteria), and currently sold as a plant growth stimulating agent. We isolated bacilli showing fibrinolytic activities from Myeolchi (anchovy) Jeotgal, a popular traditional Korean fermented seafood prepared from anchovy (Engraulis japonica) and salt [13]. Among the isolates, CJ1 showed the strongest activity. We identified CJ1 as B. velezensis, and studied its main fibrinolytic enzyme. We cloned the structural gene, aprECJ1, from the genome of B. velezensis CJ1, and successfully overexpressed in B. subtilis WB600.

\section{Materials and Methods}

\section{Isolation and Identification of $B$. velezensis $\mathrm{CJ} 1$ from Myeolchi Jeotgal}

Myeolchi (anchovy, Engraulis japonica) Jeotgal was purchased at a local traditional market in Jinju, Gyeongnam province, Republic of Korea, in 2020. Ten g of Myeolchi Jeotgal was mixed with $90 \mathrm{ml}$ of $0.1 \%$ peptone water, homogenized by using a stomacher (Stomacher ${ }^{\circledR} 80$, USA), and serially diluted with peptone water. Diluted samples were spreaded on Luria-Bertani (LB, tryptone $10 \mathrm{~g}$, yeast extract $5 \mathrm{~g}, \mathrm{NaCl} 10 \mathrm{~g}$ per liter, $\mathrm{pH}$ 7.0) agar plates. The plates were incubated for $48 \mathrm{~h}$ at $30^{\circ} \mathrm{C}$. Colonies with typical Bacillus morphologies were selected and spotted onto LB plates with skim milk $(1 \%, \mathrm{w} / \mathrm{v})$ (Acumedia, USA). Isolates showing strong proteolytic activities were further investigated for the fibrinolytic activities by fibrin plate method [14]. Colonies showing strong fibrinolytic activities were identified by molecular biological methods. Chromosomal DNA was prepared from $18 \mathrm{~h}$ culture on LB broth by phenolchloroform extraction method. 16S rRNA genes were amplified using primers: bac-F (5'-CGGCGTGCCTAATACATGCAAG-3'), and bac-R (5'-GGCATGCTGATCCGCATTACTA-3') [15]. $\operatorname{recA}$ was amplified using primers: recA-F (5'-TGAGTGATCGTCAGGCAGCCT-
TAG-3'), and recA-R (5'-CYTBRGATAAGAR TACCAWGMACCGC-3') [15]. PCR was done in $50 \mu \mathrm{l}$ volume consisting of $2 \mu \mathrm{l}$ template DNA, $2 \mu \mathrm{l}$ primers $(10 \mu \mathrm{M}$ each), $5 \mu \mathrm{l}$ dNTPs (0.25 mM each), and $0.5 \mu \mathrm{l} \mathrm{Ex} \mathrm{Taq}$ DNA polymerase (Takara, Japan). PCR conditions were as follows: initial denaturation at $94^{\circ} \mathrm{C}$ for $5 \mathrm{~min}$ followed by 30 cycles consisting of $94^{\circ} \mathrm{C}$ for $30 \mathrm{~s}, 58^{\circ} \mathrm{C}$ for $30 \mathrm{~s}$, and $72^{\circ} \mathrm{C}$ for $1 \mathrm{~min}$, and final extension at $72^{\circ} \mathrm{C}$ for $4 \mathrm{~min}$. Nucleotide sequences of the amplified fragments were determined and analyzed for homologous genes by BLAST (NCBI, USA).

Randomly amplified polymorphic DNA (RAPD)-PCR was done using S30 primer (5'-GTGATCGCAG-3') and Go-Taq ${ }^{\circledR}$ DNA polymerase (Promega, USA) [15]. PCR was done in $30 \mu \mathrm{l}$ volume consisting of $2 \mu \mathrm{l}$ template DNA, $2 \mu \mathrm{l}$ S30 primer $(10 \mu \mathrm{M})$, and $15 \mu \mathrm{l}$ Go Taq $^{\circledR}$ green master mix. PCR conditions were as follows: initial denaturation at $94^{\circ} \mathrm{C}$ for $5 \mathrm{~min}$ followed by 40 cycles consisting of $94^{\circ} \mathrm{C}$ for $15 \mathrm{~s}, 32^{\circ} \mathrm{C}$ for $15 \mathrm{~s}$, and $72^{\circ} \mathrm{C}$ for $2 \mathrm{~min}$, and final extension at $72^{\circ} \mathrm{C}$ for $4 \mathrm{~min}$.

\section{Growth, fibrinolytic activity and salt tolerance of $B$. velezensis $\mathrm{CJ} 1$}

B. velezensis CJ1 was cultured on 4 different media: LB broth, Brain Heart Infusion (BHI, Becton, Dickinson and Company, USA), nutrient broth (NB, Becton, Dickinson and Company), and tryptic soy broth (TSB, Becton, Dickinson and Company) at $37^{\circ} \mathrm{C}$ with shaking for $96 \mathrm{~h}$. Growth of each culture was monitored by measuring the $\mathrm{OD}_{600}$ value at $12 \mathrm{~h}$ intervals. Aliquot of culture was taken at each time point, and centrifuged at $12,000 \times \mathrm{g}$ for $10 \mathrm{~min}$ at $4^{\circ} \mathrm{C}$, and the supernatant was filtered using a $0.45 \mu \mathrm{m}$ filter (Sartorius Stedim, Germany). The filtered supernatant was used as a sample for fibrinolytic activity measurement by fibrin plate method [14]. Fibrinogen (Sigma, USA) (1.2\%, w/v) was mixed with $7 \mathrm{ml} 1 \mathrm{M}$ phosphate-buffered saline (PBS, $\mathrm{pH} 7.0$ ), and $0.1 \mathrm{ml}$ thrombin solution (100 NIH units/ $\mathrm{ml}$, Sigma) and the solution was mixed with $7 \mathrm{ml} 2 \%$ (w/v) agarose solution. Next, the mixed solutions were poured into a plate, and stood for $1 \mathrm{~h}$ at room temperature (RT) to allow fibrin clot formation. Holes on a fibrin plate were made using a capillary glass tube, then samples were applied into each hole and the plate was incubated for $18 \mathrm{~h}$ at $37^{\circ} \mathrm{C}$. The fibrinolytic activity was measured from the diameter of transparent zone on the fibrin plate 
and compared with those obtained from plasmin at 2$40 \mathrm{mU}$.

\section{SDS-PAGE and fibrin zymography}

B. velezensis CJ1 was cultivated in LB broth for $36 \mathrm{~h}$ at $37^{\circ} \mathrm{C}$. Aliquots taken at $12 \mathrm{~h}$ intervals were centrifuged and filtered as described above. Filtered supernatants were used for SDS-PAGE and fibrin zymography. For SDS-PAGE, supernatant was concentrated by trichloroacetic acid (TCA) precipitation method, and $10 \mu \mathrm{g}$ was loaded into each well. For fibrin zymography, supernatant (1 $\mu \mathrm{g})$ was loaded without TCA concentration. Electrophoresis was done using acrylamide gels consisting of 5\% stacking gel and $12 \%$ separating gel. Fibrin gel was prepared by mixing $0.12 \%$ (w/v) fibrinogen and $10 \mu \mathrm{l}$ thrombin (10 NIH units $/ \mathrm{ml}$ ) with the $12 \%$ polyacrylamide gel solution. After electrophoresis at $10 \mathrm{~mA}$ and $4{ }^{\circ} \mathrm{C}$, the gel was incubated for $30 \mathrm{~min}$ at RT in $50 \mathrm{mM}$ Tris-HCl buffer ( $\mathrm{pH} 7.4$ ) containing $2.5 \%$ (v/v) Triton X100. Gel was washed with distilled water for $30 \mathrm{~min}$ and incubated overnight at $37^{\circ} \mathrm{C}$ in $30 \mathrm{mM}$ Tris- $\mathrm{HCl}$ buffer ( $\mathrm{pH} 7.4$ ) containing $0.02 \%(\mathrm{w} / \mathrm{v})$ of $\mathrm{NaN}_{3}$. The gel was stained with coomassie blue R-250.

\section{Cloning of aprECJ1}

B. velezensis CJ1 was cultivated in LB broth for $12 \mathrm{~h}$ at $37^{\circ} \mathrm{C}$. Cells were collected by centrifugation at $12,000 \times \mathrm{g}$ for $10 \mathrm{~min}$ at $4^{\circ} \mathrm{C}$. Cell pellet was resuspended in $1 \mathrm{ml}$ of lysis buffer (10 mM Tris-HCl, pH 8.0, $10 \mathrm{mM}$ EDTA, $100 \mathrm{mM} \mathrm{NaCl}, 2 \% \mathrm{SDS}$ ) with $40 \mu \mathrm{l}$ of proteinase $\mathrm{K}$ (Sigma) and stood for $30 \mathrm{~min}$ at $55^{\circ} \mathrm{C}$. Suspension was extracted with phenol and chloroform mixture, and ethanol precipitation was done for DNA recovery. DNA was resuspended in small volume of sterile water and used as a template for PCR. To amplify aprECJ1 from $B$. velezensis $\mathrm{CJ} 1$ genome, PCR was done by using a primer pair: CH51-F (5'-AGGATCCCAAGAGAGCGATTGCGGCTGTGTAC-3', BamHI site underlined) and CH51-R (5'-AGAATTCTTCAGAGGGAGCCACCCGTCGATCA3', EcoRI site underlined) [16]. The PCR reaction mixture $(50 \mu \mathrm{l})$ contained $1 \mu \mathrm{l}$ template DNA, $1 \mu \mathrm{l}$ each primer $(10 \mu \mathrm{M}), 5 \mu \mathrm{l}$ dNTPs $(0.25 \mathrm{mM})$, and $0.5 \mu \mathrm{l}$ Ex Taq DNA polymerase (Takara, Tokyo, Japan). Amplification conditions were as follows: $94^{\circ} \mathrm{C}$ for $5 \mathrm{~min}, 30$ cycles of $94^{\circ} \mathrm{C}$ for $30 \mathrm{sec}, 56^{\circ} \mathrm{C}$ for $30 \mathrm{sec}, 72^{\circ} \mathrm{C}$ for $40 \mathrm{sec}$, and a final extension at $72^{\circ} \mathrm{C}$ for $5 \mathrm{~min}$. The amplified fragment was ligated with pHY300PLK, an E. coli-Bacillus shuttle vector $\left(4.87 \mathrm{~kb}, \mathrm{Tc}^{\mathrm{R}}\right)$ after digested with Bam $\mathrm{HI}$ and EcoRI. Ligation mixture was used to transform E. coli DH5a competent cells by electroporation $(200 \Omega .21 \mathrm{kV} /$ cm). Plasmid DNA preparation from E. coli DH5a, restriction enzyme digestion, preparation of competent cells, and agarose gel electrophoresis were performed according to the published methods [17].

\section{Heterologous expression of aprECJ1 in B. subtilis WB600}

A $1.3 \mathrm{~kb}$ aprECJ1 gene amplified as above was ligated into pHY300PLK and the resulting recombinant plasmid was introduced into B. subtilis WB600 competent cells by electroporation (200 $\Omega .21 \mathrm{kV} / \mathrm{cm})$. A B. subtilis WB600 transformant (TF) was obtained and inoculated into LB broth containing tetracycline $(15 \mu \mathrm{g} / \mathrm{ml})$ for $96 \mathrm{~h}$ at $37^{\circ} \mathrm{C}$. Growth and fibrinolytic activity of culture was measured at $12 \mathrm{~h}$ intervals. B. velezensis CJ1 and $B$. subtilis WB600 [pHY300PLK] were used as controls. SDS-PAGE and fibrin zymography were done for culture supernatant as described above.

\section{Results and Discussion}

\section{Isolation and Identification of B. velezensis CJ1 from Myeolchi Jeotgal}

Among about 1,000 bacilli isolates, 15 isolates with strong proteolytic activities were selected first, and then tested for fibrinolytic activities. Finally, one isolate, CJ1. showing the strongest fibrinolytic activity was selected for further studies (data not presented). CJ1 was Gram positive, rod shaped and appeared as the typical Bacillus colony on LB agar plates. The $16 \mathrm{~s}$ rRNA gene sequence (1,219 nucleotides, MW792221) was determined and BLAST analysis indicated that the gene showed 99\% identities to those of $B$. velezensis and $B$. amyloliquefaciens strains. recA gene sequence (749 nucleotides, MW792222) showed $100 \%$ identities to those of $B$. velezensis and $B$. amyloliquefaciens strains. 16S rRNA and recA genes sequencing could not identify the species of CJ1. It is well-known that closely related Bacillus species are difficult to be identified either by traditional classification methods or molecular biological methods such as $16 \mathrm{~S}$ rRNA gene sequencing [15]. To clarify its species status, RAPD-PCR was done using S30 primer [15]. Two bands of 700 and $1,800 \mathrm{bp}$ in size were amplified from CJ1 


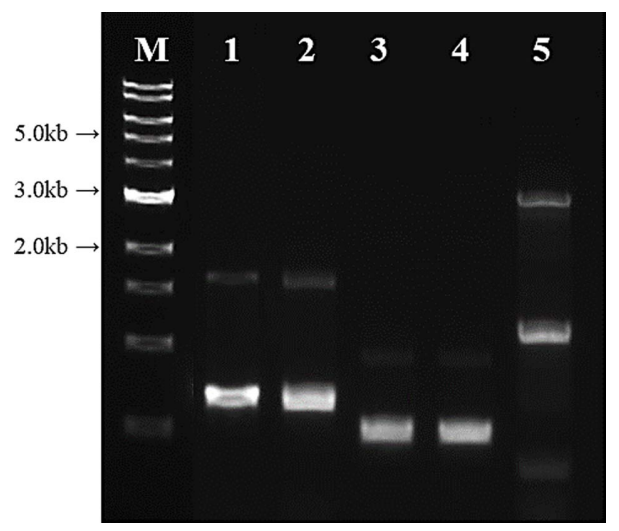

Fig. 1. RAPD-PCR profiles of Bacillus spp. CJ1 and related Bacillus spp. $M$, size marker (iVDye I kb DNA ladder, GenDEPOT, Katy, TX, USA); 1, Bacillus spp. CJ1; 2, B. velezensis ATCC17177; 3, B. subtilis ATCC33608; 4, B. subtilis ATCC33234; 5, B. amyloliquefaciens ATCC 23350 . Agarose gel $(0.8 \%)$ was used to show the RAPDPCR profiles.

chromosomal DNA, which was the same profile with that from B. velezensis ATCC17177 (Fig. 1). From these results, CJ1 was identified as B. velezensis and accordingly named B. velezensis CJ1.

\section{Growth, Fibrinolytic Activity and Salt Tolerance of $B$. velezensis $\mathrm{CJ} 1$}

B. velezensis $\mathrm{CJ} 1$ grew well on $\mathrm{LB}, \mathrm{BHI}$, and TSB, and the $\mathrm{OD}_{600}$ values reached $1.4-1.6$ at $12 \mathrm{~h}$ cultivation. Culture on NB remained at lower values, and the $\mathrm{OD}_{600}$ value at $96 \mathrm{~h}$ was 0.98 whereas those of other cultures were $1.7-1.8$ at $96 \mathrm{~h}$ (Fig. 2A). LB was the best medium for the fibrinolytic activity. Culture on LB showed the highest fibrinolytic activity $(102.94 \mathrm{mU} / \mathrm{\mu l})$ at $48 \mathrm{~h}$ (Fig. 2B). After $48 \mathrm{~h}$, the activity decreased gradually until $60 \mathrm{~h}$ and very low activities were detected between 72 and $96 \mathrm{~h}$. The fibrinolytic profiles of B. velezensis CJ1 were variable depending upon culture medium, indicating components of culture affected the fibrinolytic activities.

B. velezensis CJ1 grew well at $10-12 \% \mathrm{NaCl}$, and the $\mathrm{OD}_{600}$ values were $1.4-1.6$ at $144 \mathrm{~h}$ (Fig. 3). B. velezensis CJ1 grew slowly at $15 \% \mathrm{NaCl}$ and the highest $\mathrm{OD}_{600}$ value was 1.07 at $96 \mathrm{~h}$. B. velezensis CJ1 did not grow until $48 \mathrm{~h}$ at $17 \% \mathrm{NaCl}$, and then grew slowly, and the $\mathrm{OD}_{600}$ value was 0.16 at $144 \mathrm{~h}$. B. velezensis CJ1 didn't grow at $20 \%$ salt for $144 \mathrm{~h}$. Considering its salt tolerance, B. velezensis CJ1 could be used as a starter for
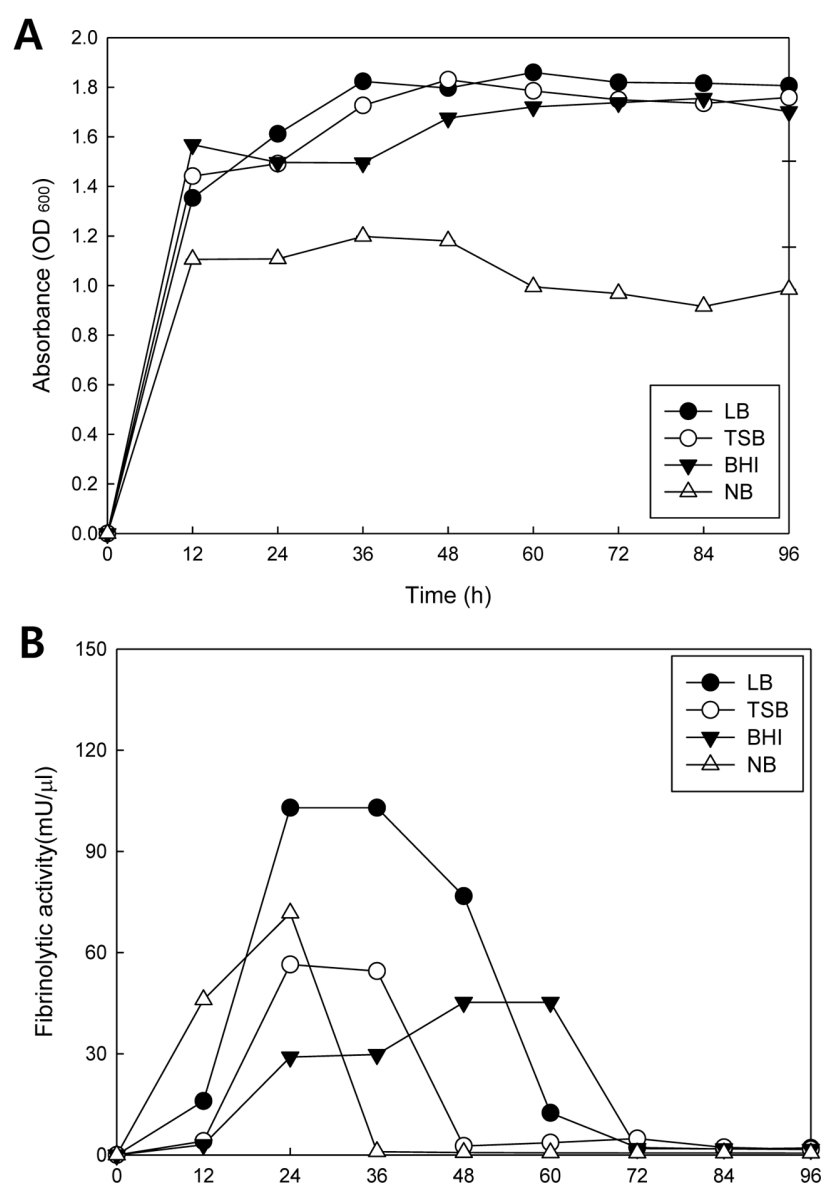

Fig. 2. Growth (A) and fibrinolytic activity (B) of $B$. velezensis CJ1 for 96 h cultivation on different culture media. $O, L B$; $\mathrm{O}, \mathrm{TSB} ; \boldsymbol{\nabla}, \mathrm{BHI}, \triangle, \mathrm{NB}$.

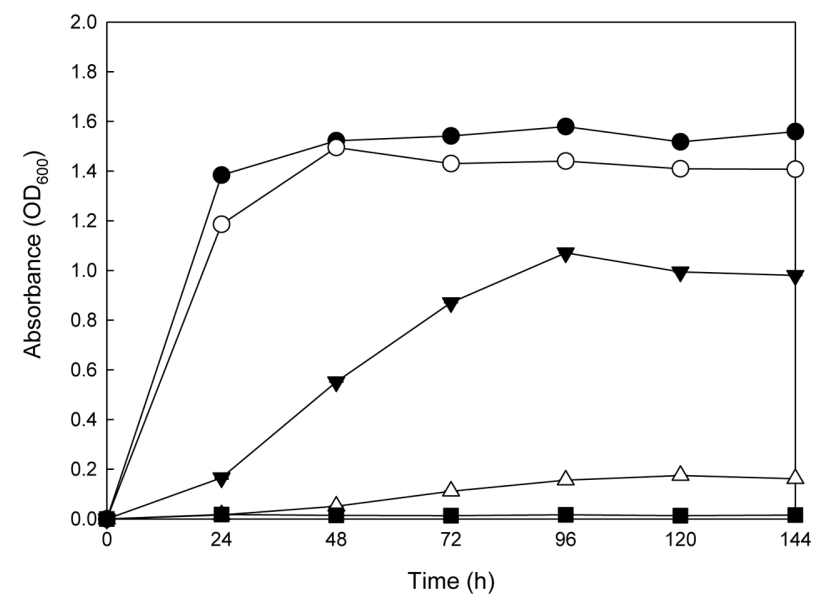

Fig. 3. Growth of $B$. velezensis $\mathrm{CJ} 1$ on LB broth with different $\mathrm{NaCl}$ contents. $-10 \% \mathrm{NaCl} ; \bigcirc, 12 \% \mathrm{NaCl} ; \boldsymbol{\nabla}, 15 \% \mathrm{NaCl} ; \triangle, 17 \%$ $\mathrm{NaCl} ; \mathbf{\square}, 20 \% \mathrm{NaCl}$. 


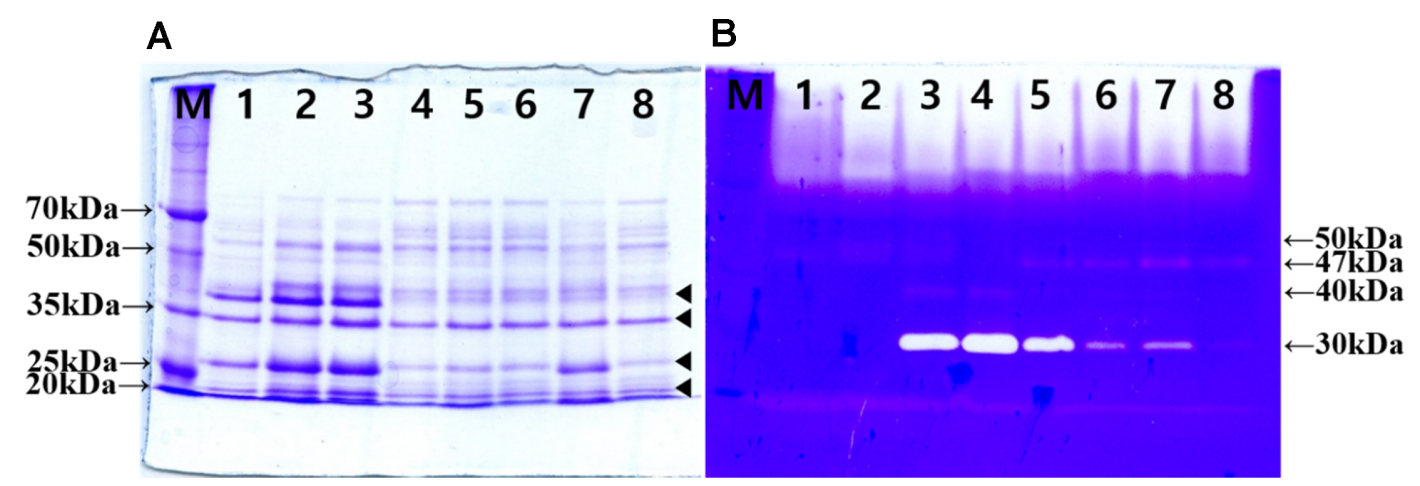

Fig. 4. SDS-PAGE (A) and fibrin zymography (B) of culture supernatant of $\boldsymbol{B}$. velezensis $\mathbf{C J 1}$. B. velezensis $\mathrm{CJ} 1$ was grown in $\mathrm{LB}$ broth at $37^{\circ} \mathrm{C}$ up to $96 \mathrm{~h}$. Aliquot was taken at $12 \mathrm{~h}$ intervals. M, Dokdo-marker broad-range (EBM-1034, ELPIS, Deajeon, Korea); 1 , 12 h; 2, 24 h; 3, 36 h; 4, 48 h; 5, 60 h; 6, 72 h; 7, 84 h; 8, 96 h.

fermented foods where the salt concentration does not exceed $15 \%$.

\section{SDS-PAGE and fibrin zymography}

On a coomassie blue stained gel, the intensities of 4 bands $(38,35,27$, and $22 \mathrm{kDa})$ increased as the culture entered into the stationary phase of growth between $24 \mathrm{~h}$ and $36 \mathrm{~h}$ (Fig. $4 \mathrm{~A}$ ). The intensities of the bands decreased after $36 \mathrm{~h}$. The intensities of 22 and $27 \mathrm{kDa}$ bands slightly increased at $84 \mathrm{~h}$ and then decreased again. Fibrinolytic activity of $B$. velezensis $\mathrm{CJ} 1$ on $\mathrm{LB}$ broth was at the highest between $24 \mathrm{~h}$ and $36 \mathrm{~h}$ (Fig. $2 \mathrm{~B})$, which period overlapped the time points where band intensities of 4 proteins were stronger.

On fibrin zymogram, 4 active bands were observed, and they were 50, 47, 40, and $30 \mathrm{kDa}$ in size (Fig. 4B). The intensity of the $30 \mathrm{kDa}$ band was at the highest at $48 \mathrm{~h}$ followed by at $36 \mathrm{~h}$ and $60 \mathrm{~h}$. At $72 \mathrm{~h}$ and thereafter, the band intensity reduced. A $50 \mathrm{kDa}$ band was observed for the first $36 \mathrm{~h}$ only, and a $47 \mathrm{kDa}$ band observed at $60 \mathrm{~h}$ and thereafter. A $40 \mathrm{kDa}$ band was observed at $36 \mathrm{~h}$ and $48 \mathrm{~h}$. The changes in fibrin zymogram reflect changes in proteolytic enzymes and their activities inside B. velezensis CJ1 during growth on LB broth. Several fibrinolytic enzymes are synthesized, and each enzyme may have specific time points where the enzyme becomes fully active. Also a large fibrinolytic enzyme is subjected to posttranslational processings at $\mathrm{N}$ - or $\mathrm{C}$ terminus or both, generating small sized derivatives which are still active. More studies are necessary to elucidate how many different fibrinolytic proteases are secreted by $B$. velezensis CJ1 and how their activities change during growth. It is known that Bacillus species secrete several proteases such as Apr, Npr, Epr, Mpr, and Vpr [18]. Some enzymes are subjected to processing at either $\mathrm{N}$-terminus or C-terminus, generating small fragments. To identify the processed derivatives, it is necessary to determine the amino acid sequences of each band on SDS-PAGE gel.

The strength of fibrinolytic activity of a sample can be estimated roughly from the size of the halo at the top part of the fibrin gel. The halo is suspected to be caused by binding of fibrinolytic enzymes to fibrin in the gel [19]. The $30 \mathrm{kDa}$ protein on the fibrin zymogram might be one of the major enzymes responsible for the fibrinolytic activity of $B$. velezensis CJ1 at $36-60 \mathrm{~h}$. It is noteworthy that the $30 \mathrm{kDa}$ band was missing at $12 \mathrm{~h}$ and $24 \mathrm{~h}$ time points. It might be a degradation or processed product from a fibrinolytic enzyme such as Vpr from $B$. subtilis SJ4 where the mature $\operatorname{Vpr}(68.5 \mathrm{kDa})$ was subjected to autoprocessing and smaller proteins in the range of $33-20 \mathrm{kDa}$ were generated [20]. The $30 \mathrm{kDa}$ band was not located on the SDS-PAGE gel, and this might be due to the less sensitivity of coomassie blue stained gel. More studies are necessary on the identification of these bands on fibrin zymogram.

\section{Cloning of aprECJ1}

A $1.3 \mathrm{~kb}$ PCR fragment was cloned and the nucleotide sequence was determined (MW792223). Sequence analysis located an ORF which could encode a protein consisting of 382 amino acids (Fig. 5). BLAST analysis confirmed that the translated gene product was an AprE type protease. AprECJ1 showed 100-99\% amino acid 
GATTGATATACCTAAATAGAAATAAAACAAACTGAAAAAAATTGGGTCTACTAAAATATT 60 ATTCCATACTA IACAATTAATCCACAGAATAATCTGTCTATTGGTTATTCTGCAAATGAA 120 $-10$

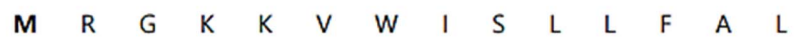
AAAAGGAGTGGATAAAGAGTGAGAGGCAAAAAGGTATGGATCAGTTTGCTGTTTGCTTTA 180 RBS

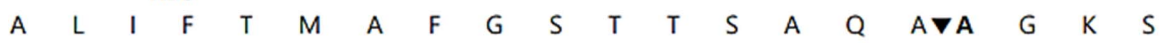
GCGTTAATCTTTACGATGGCGTTCGGCAGCACGACTTCTGCCCAGGCTGCAGGGAAATCA 240 $\begin{array}{llllllllllllllllllll}N & G & E & K & K & Y & I & V & G & F & K & Q & T & M & S & T & M & S & A & A\end{array}$ AACGGGGAAAAGAAATATATTGTCGGATTTAAGCAGACAATGAGCACGATGAGCGCCGCC 300 $\begin{array}{llllllllllllllllllll}K & K & K & D & V & I & S & E & K & G & G & K & V & E & K & Q & F & K & Y & V\end{array}$ AAGAAAAAAGATGTCATTTCTGAAAAAGGCGGGAAAGTGGAAAAGCAATTCAAATATGTA 360 $\begin{array}{llllllllllllllllllll}D & A & A & S & A & T & L & N & E & K & A & V & K & E & L & K & K & D & P & S\end{array}$ GACGCAGCTTCAGCTACATTAAATGAAAAAGCTGTAAAAGAGCTGAAAAAAGACCCTAGC 420

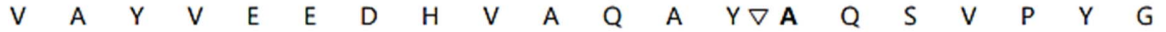
GTCGCTTACGTTGAAGAAGATCACGTTGCACAGGCGTACGCGCAGTCCGTGCCTTACGGC 480 $\begin{array}{lllllllllllllllllllll}V & S & Q & I & K & A & P & A & L & H & S & Q & G & F & T & G & S & N & V & K\end{array}$ GTATCACAGATTAAAGCCCCTGCTCTGCACTCTCAAGGCTTCACCGGATCAAATGTTAAA 540 $\begin{array}{llllllllllllllllllll}V & A & V & I & D & S & G & I & D & S & S & H & P & D & L & K & V & A & G & G\end{array}$ GTAGCGGTTATCGACAGCGGTATCGATTCTTCTCATCCTGATTTAAAGGTAGCAGGCGGA 600 $\begin{array}{llllllllllllllllllllll}A & S & M & V & P & S & E & T & N & P & F & Q & D & N & N & S & H & G & T & H\end{array}$ GCCAGCATGGTTCCTTCTGAAACAAATCCTTTCCAAGATAACAACTCTCACGGAACTCAC 660 $\begin{array}{llllllllllllllllllll}V & A & G & T & V & A & A & L & N & N & S & V & G & V & L & G & V & A & P & S\end{array}$ GTTGCCGGTACAGTTGCGGCTCTTAATAACTCAGTCGGTGTATTAGGCGTTGCGCCAAGC 720 $\begin{array}{llllllllllllllllllll}A & S & L & Y & A & V & K & V & L & G & A & D & G & S & G & Q & Y & S & W & I\end{array}$ GCATCTCTTTACGCTGTAAAAGTTCTCGGCGCTGACGGTTCCGGCCAGTACAGCTGGATC 780 $\begin{array}{llllllllllllllllllll}\text { I } & N & G & \text { I } & E & W & A & \text { I } & A & N & N & M & D & V & \text { I } & N & M & S & L & G\end{array}$ ATTAACGGAATTGAGTGGGCGATCGCAAACAATATGGACGTTATTAACATGAGCCTCGGC 840 $\begin{array}{llllllllllllllllllll}G & P & S & G & S & A & A & L & K & A & A & V & D & K & A & V & A & S & G & V\end{array}$ GGACCTTCTGGTTCTGCAGCGTTAAAAGCGGCAGTTGACAAAGCCGTTGCTTCCGGCGTC 900 $\begin{array}{llllllllllllllllllll} & V & V & A & A & A & G & N & E & G & T & S & G & G & S & S & T & V & G & Y\end{array}$ GTAGTGGTTGCGGCAGCCGGTAACGAAGGCACTTCCGGCGGCTCAAGCACAGTGGGCTAC 960 $\begin{array}{llllllllllllllllllll}P & G & K & Y & P & S & V & I & A & V & G & A & V & N & S & S & N & Q & R & A\end{array}$ CCTGGTAAATACCCTTCTGTCATTGCGGTAGGCGCTGTTAACAGCAGCAACCAAAGAGCA 1020 $\begin{array}{llllllllllllllllllll}S & F & S & S & V & G & S & E & L & D & V & M & A & P & G & V & S & I & Q & S\end{array}$ TCTTTCTCAAGCGTAGGTTCTGAGCTTGATGTCATGGCACCAGGCGTCTCTATCCAAAGC 1080 $\begin{array}{llllllllllllllllllll}T & L & P & G & N & K & Y & G & A & Y & N & G & T & S & M & A & S & P & H & V\end{array}$ ACGCTTCCTGGAAACAAATACGGCGCGTACAATGGTACGTCAATGGCATCTCCGCACGTT 1140

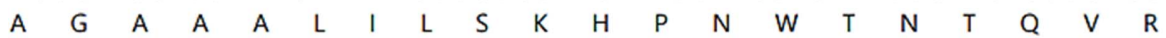
GCCGGAGCGGCTGCTTTGATTCTTTCTAAGCACCCGAACTGGACAAACACTCAAGTCCGC 1200 $\begin{array}{llllllllllllllllllll}S & S & L & E & N & T & T & T & K & L & G & D & A & F & Y & Y & G & K & G & L\end{array}$ AGCAGTTTAGAAAACACCACTACAAAACTTGGTGATGCTTTCTACTACGGAAAAGGCTG 1260 I $N \quad V \quad Q \quad A \quad A \quad A \quad Q$

ATCAACGTACAGGCGGCAGCTCAGTAAAACATIAAAAACCGGCGTCGGCCATGGCCCCGC 1320

Fig. 5. Nucleotide sequence of aprECJ1. The nucleotide sequence and deduced amino acid sequence of aprECJ1 are shown. Tentative promoter sequences (-35 and -10) and RBS (ribosome binding site) are underlined. A possible transcription terminator is also underlined. The end of pre $(\boldsymbol{\nabla})$ and pro sequence $(\nabla)$ are marked. The first amino acid of proenzyme and mature enzyme are marked in bold characters.

identities with multispecies S8 family peptidase of Bacillus (100\% with WP_003155195; 99\% with WP_024085087 and WP_077722018). AprECJ1 also showed 99-98\% amino acid identities with S8 family peptidase of $B$. velezensis strains where the genome sequences were determined (99\% with WP_070081588, WP_179155972, WP_044802764, and WP_082997797; 98\% with WP_065180663 and WP_173613606). These
AprEs from B. velezensis strains are tentative proteins from annotated genes. AprECJ1 also showed high amino acid sequence identities with fibrinolytic enzymes characterized previously by us, i.e. $99 \%$ identity (379/382) with an enzyme from B. subtilis (AHN52401.1), an enzyme from B. pumilus (ATD12229.1), AprE3-17 from B. licheniformis (378/382, ACU32756.1), an alkaline serine protease from B. subtilis (377/392, QIN90910.1), and 
a fibrinolytic enzyme from B. subtilis (377/382, ATA67131.1).

AprECJ1 is synthesized as a preproform, and the active, mature form accumulates in the culture medium. The first 30 amino acids are signal sequence as judged by SignalP-5.0 (http://www.cbs.dtu.dk/services/SignalP/), and the next 77 amino acids are pro-sequence as compared with other similar enzymes. The calculated size and pI of the preproenzyme are 39,100.11 Da and 9.14, respectively. The mature enzyme consists of 275 amino acids, and its molecular weight and pI are 27,446.57 Da and 6.65 , respectively.

\section{Heterologous expression of aprECJ1 in B. subtilis WB600} aprECJ1 was overexpressed in B. subtilis WB600, a
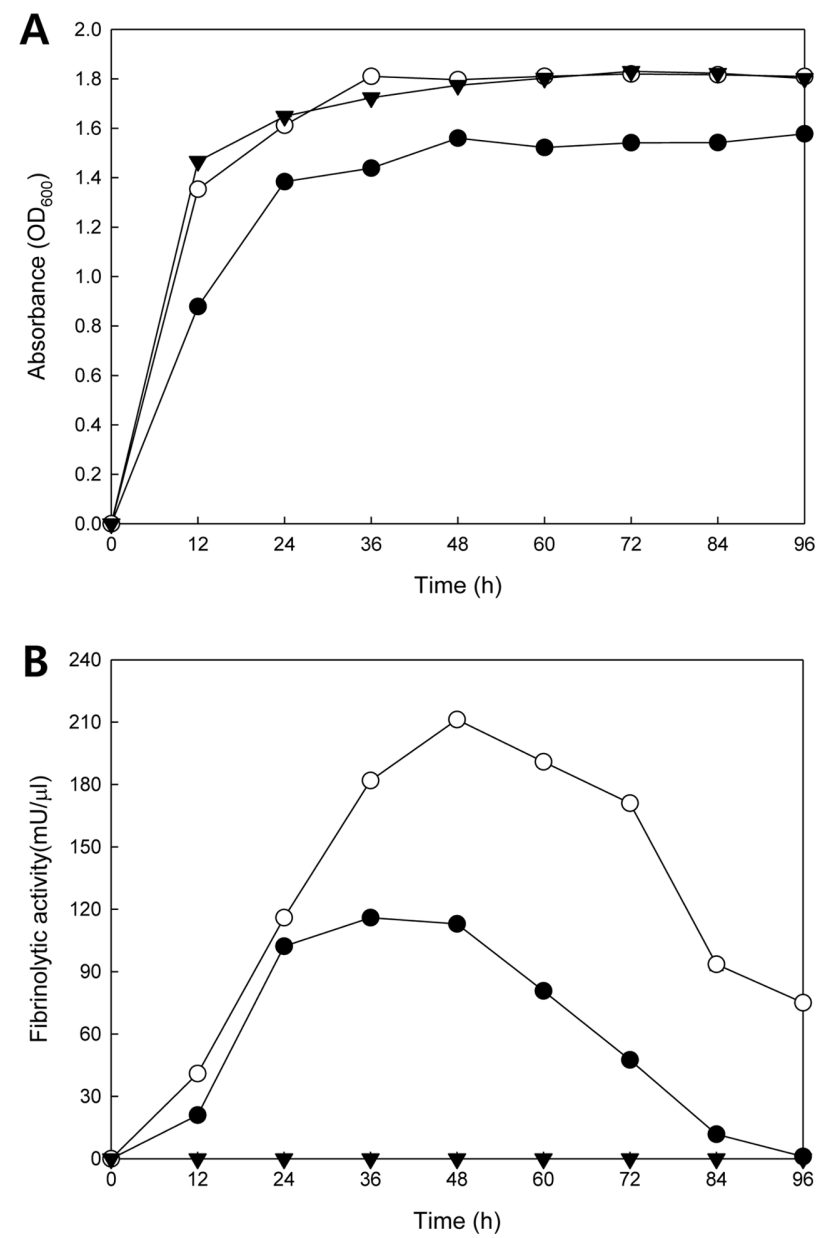

Fig. 6. Growth (A) and fibrinolytic activities (B) of B. subtilis transformants (TFs). TFs were grown on LB broth for $96 \mathrm{~h}$ at $37^{\circ} \mathrm{C} . \mathrm{OD}_{600}$ value and fibrinolytic activity were measured at $12 \mathrm{~h}$ intervals. O, B. velezensis $\mathrm{CJ} 1 ; O$, B. subtilis WB600 [pHYaprECJ1]; $\mathbf{\nabla}$, B. subtilis WB600 [pHY300PLK]. mutated strain where 6 extracellular protease genes were inactivated [21]. B. subtilis WB600 TF harboring pHYaprECJ1 (pHY300PLK with aprECJ1) showed the same growth pattern with control, B. subtilis WB600 [pHY300PLK] on LB broth (Fig. 6A). B. velezensis CJ1 grew slower than $B$. subtilis strains, and the absorbance values remained lower than those of $B$. subtilis strains (Fig. 6A). B. subtilis WB600 [pHYaprECJ1] showed higher fibrinolytic activity than B. velezensis CJ1 (Fig. 6B). B. subtilis WB600 [pHYaprECJ1] showed 1.8 fold higher activity than $B$. velezensis $\mathrm{CJ} 1$ at $48 \mathrm{~h}$. This was caused by the high copy number of aprECJ1 in a plasmid vector. If optimization efforts are made to increase gene expression level of aprECJ1 by promoter replacement with stronger promotors or use of other plasmid vectors, the fibrinolytic activity of $B$. subtilis $\mathrm{TF}$ will be increased further. B. subtilis WB600 [pHYaprECJ1] showed the highest activity $(211.45 \mathrm{mU} / \mathrm{\mu l})$ at $48 \mathrm{~h}$, and the second highest activity $(192.93 \mathrm{mU} / \mathrm{\mu l})$ at $60 \mathrm{~h}$. After $48 \mathrm{~h}$, the activity decreased rapidly, and showed $75.33 \mathrm{mU} / \mathrm{\mu l}$ at $96 \mathrm{~h}$. For B. velezensis CJ1, the highest activity $(115.93 \mathrm{mU} / \mathrm{\mu l})$ was observed at $36 \mathrm{~h}$, and the second highest activity $(112.93 \mathrm{mU} / \mathrm{\mu l})$ at $48 \mathrm{~h}$. B. subtilis WB600 [pHY300PLK] did not show any activity during the $96 \mathrm{~h}$ incubation period. The $27 \mathrm{kDa}$ mature form of AprECJ1 was observed in both SDS-PAGE gel (Fig. 7A, lane 1 and 2) and fibrin zymogram (Fig. 7B), but was not observed in control (Fig. 7, lane 5, 6). The result showed that AprECJ1 was properly processed in a heterologous host.

B. velezensis CJ1 was isolated from Myeolchi Jeotgal and showed strong fibrinolytic activity. The strain grew well in the presence of salt up to $15 \%$. The strain and its fibrinolytic gene, aprECJ1, seem promising as a starter for fermented food such as Jeotgal and for production of fibrinolytic enzyme for the possible treatment of thrombosis. Fibrinolytic enzymes secreted by Bacillus species such as AprECJ1 show very high amino acid sequence homologies with other proteases. But a few amino acid changes might cause significant differences in the fibrinolytic activities. For example, nattokinase (AprN) and subtilisin $\mathrm{E}$ are different in just 2 amino acids but only nattokinase shows strong fibrinolytic activity [22, 23]. For this reason, more studies are necessary on the isolation of novel bacilli from diverse natural environments including fermented foods and characterization of their 
A

B

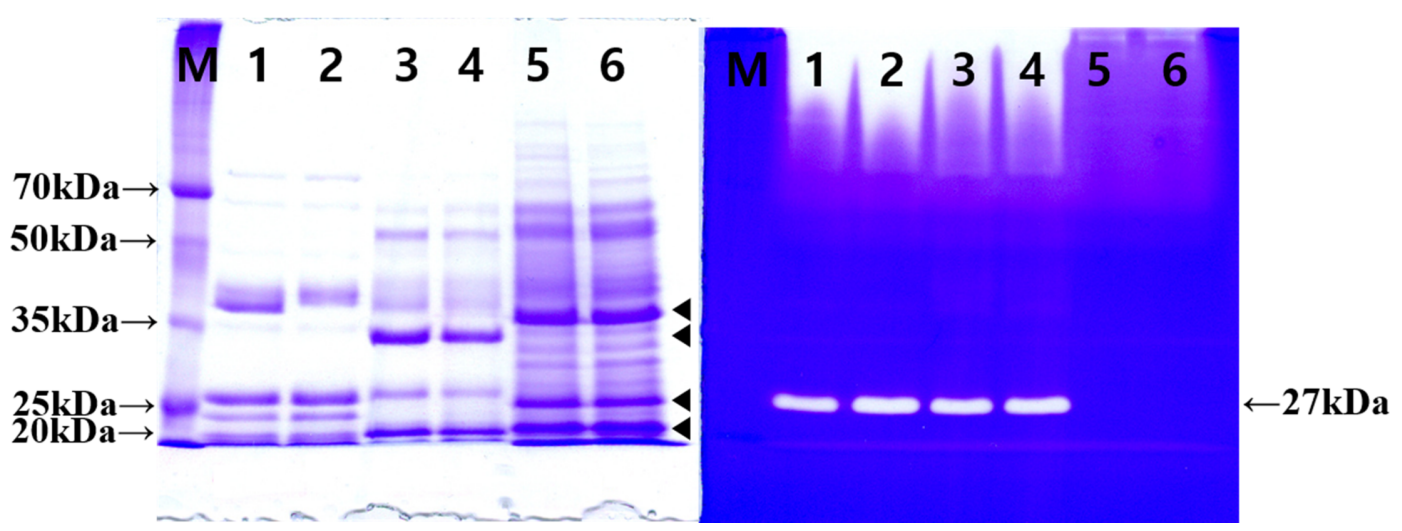

Fig. 7. SDS-PAGE (A) and fibrin zymography (B) of culture supernatant from $B$. subtilis TFs. M, Dokdo-marker broad-range (EBM-1034, ELPIS, Daejeon, Korea). B. subtilis WB600 [pHYaprECJ1] at $48 \mathrm{~h}$ (lane 1), and $60 \mathrm{~h} \mathrm{(2);} \mathrm{B.} \mathrm{velezensis} \mathrm{CJ1} \mathrm{at} 48 \mathrm{~h}$ (3), and $60 \mathrm{~h}$ (4); B. subtilis WB600 [pHY300PLK] at $48 \mathrm{~h}(5)$, and $60 \mathrm{~h}(6)$.

fibrinolytic enzymes. The expected results will help to improve our understanding on the diversity and characteristics of fibrinolytic enzymes, and will pave a road for full utilization of these enzymes.

\section{Acknowledgments}

This work was supported by the Basic Science Research Program through the National Research Foundation of Korea (NRF) funded by the Ministry of Education (2017R1D1A1B03030037) and also by a NRF grant funded by the Korea government (MSIT) (No. NRF2020R1A2C100826711). Yoo JY, Yao Z, Lee SJ, and Jeon HS were supported by BK21 four program, MOE, Republic of Korea.

\section{Conflict of Interest}

The authors have no financial conflicts of interest to declare.

\section{References}

1. Kho CW, Park SG, Cho S, Lee DH, Myung PK, Park BC. 2005. Confirmation of $\mathrm{Vpr}$ as a fbrinolytic enzyme present in extracellular proteins of Bacillus subtilis. Protein Expr. Purif. 39: 1-7.

2. Chen H, McGowan EM, Ren N, Lal S, Nassif N, Shad-Kaneez F, et al. 2018. Nattokinase: a promising alternative in prevention and treatment of cardiovascular diseases. Biomark. Insights 13: 1177271918785130.

3. Uesugi Y, Usuki H, Iwabuchi M, Hatanaka T. 2011. Highly potent fibrinolytic serine protease from Streptomyces. Enzyme Microb. Technol. 48: 7-12.

4. Danilova L, Sharipova M. 2020. The practical potential of bacilli and their enzymes for industrial production. Front. Microbiol. 11:
1782.

5. Weng Y, Yao J, Sparks S, Wang KY. 2017. Nattokinase: an oral antithrombotic agent for the prevention of cardiovascular disease. Int. J. Mol. Sci. 18: 523.

6. Kurosawa Y, Nirengi S, Homma T, Esaki K, Ohta M, Clark JF, et al. 2015. A single-dose of oral nattokinase potentiates thrombolysis and anti-coagulation profiles. Sci. Rep. 5: 11601.

7. Mine Y, Wong AHK, Jiang B. 2005. Fibrinolytic enzymes in Asian traditional fermented foods. Food Res. Int. 38: 243-250.

8. Jeong SJ, Kwon GH, Chun JY, Kim JS, Park CS, Kwon DY, et al. 2007. Cloning of fibrinolytic enzyme gene from Bacillus subtilis isolated from Cheonggukjang and its expression in protease-deficient Bacillus subtilis strains. J. Microbiol. Biotechnol 17: 1018-1023.

9. Kim SH, Choi NS. 2000. Purification and characterization of subtilisin DJ-4 secreted by Bacillus sp. strain DJ-4 screened from Doen-Jang. Biosci. Biotechnol. Biochem. 64: 1722-1725.

10. Fujita M, Nomura K, Hong K, Ito Y, Asada A, Nishimuro S. 1993. Purification and characterization of a strong fibrinolytic enzyme (nattokinase) in the vegetable cheese natto, a popular soybean fermented food in Japan. Biochem. Biophys. Res. Commun. 197: 1340-1347.

11. Peng Y, Huang Q, Zhang R, Zhang YZ. 2003. Purification and characterization of a fibrinolytic enzyme produced by Bacillus amyloliquefaciens DC-4 screened from douchi, a traditional Chinese soybean food. Comp. Biochem. Physiol. Biochem. Mol. Biol. 134: 45-52.

12. Rabbee MF, Ali MS, Choi J, Hwang BS, Jeong SC, Baek KH. 2019. Bacillus velezensis: a valuable member of bioactive molecules within plant microbiomes. Molecules 24: 1046.

13. Koo OK, Lee SJ, Chung KR, Jang DJ, Yang HJ, Kwon DY. 2016. Korean traditional fermented fish products: jeotgal. J. Ethn. Foods 3: 107-116.

14. Astrup T, Mullertz S. 1952. The fibrin plate method for estimating fibrinolytic activity. Arch. Biochem. Biophys. 40: 346-351. 
15. Kwon GH, Lee HA, Park JY, Kim JS, Lim J, Park CS, et al. 2009. Development of a RAPD-PCR method for identification of Bacillus species isolated from cheonggukjang. Int. J. Food Microbiol. 129: 282-287.

16. Kim GM, Lee AR, Lee KW, Park JY, Chun J, Cha J, et al. 2009. Characterization of a $27 \mathrm{kDa}$ fibrinolytic enzyme from Bacillus amyloliquefaciens $\mathrm{CH} 51$ isolated from cheonggukjang. J. Microbiol. Biotechnol. 19: 997-1004.

17. Sambrook J, Russell DW. 2001. Molecular cloning a laboratory manual, chapter 5. 3rd Ed. pp. 1-90. Cold Spring Harbor laboratory Press, Cold Spring harbor, New York.

18. Choi NS, Chung DM, Park CS, Ahn KH, Kim JS, Song JJ, et al. 2010. Expression and identification of a minor extracellular fibrinolytic enzyme (Vpr) from Bacillus subtilis KCTC 3014. Biotechnol. Bioprocess Eng. 15: 446-452.

19. Choi NS, Chung DM, Ryu CH, Yoon KS, Maeng PJ, Kim SH. 2006.
Identification of three extracellular proteases from Bacillus subtilis KCTC 3014. J. Microbiol. Biotechnol. 16: 457-464.

20. Yao Z, Meng Y, Le HG, Lee SJ, Jeon HS, Yoo JY, et al. 2020. Cloning of a novel vpr gene encoding a minor fibrinolytic enzyme from Bacillus subtilis SJ4 and the properties of Vpr. J. Microbiol. Biotechnol. 30: 1720-1728.

21. Wu XC, Lee W, Tran L, Wong SL. 1991. Engineering a Bacillus subtilis expression-secretion system with a strain deficient in six extracellular proteases. J. Bacteriol. 173: 4952-4958.

22. Dabbagh F, Negahdaripour M, Berenjian A, Behfar A, Mohammadi F, Zamani M, et al. 2014. Nattokinase: production and application. Appl. Microbiol. Biotechnol. 98: 9199-9206.

23. Peng Y, Yang X, Zhang Y. 2005. Microbial fibrinolytic enzymes: an overview of source, production, properties, and thrombolytic activity in vivo. Appl. Microbiol. Biotechnol. 69: 126-132. 